\title{
Mosaico
}

FERNANDO RIOS

ISA MARIA F. ROSA GUARÁ*

\section{Cem anos que podem nos} ensinar muito
Com muita freqüência, damos as costas ao passado. E, neste mundo globalizado, quase toda a comunicação de massa nos remete ao futuro, como se apenas lá estivessem as razões de nossa felicidade, baseada quase que exclusivamente em aquisição de bens materiais: "Compre e será feliz."

Nesse turbilhão de dados e informações, esquecemo-nos de que, hoje e sempre, vivemos em processo. Nada existe em si. Tudo o que podemos observar está em movimento. E, nisso, incluímos nossas vidas, nossas escolas, nossas crianças.

Como viviam nossas crianças no começo do século passado? Como éramos nós, em nossa infância? Será que nos lembramos dos nossos primeiros tempos e somos capazes de refletir sobre as muitas causas das diversas mudanças em nossas cidades? Para complementar os artigos que Cadernos CENPEC oferece aos seus leitores sobre A segunda etapa do ensino fundamental, selecionamos textos, ] e, principalmente, filmes e livros que nos remetem ao século XX. Estamos aproximando e mostrando as crianças de Paris, México, Salvador, São Paulo, Rio de Janeiro, Paraíba que viveram em diferentes tempos e espaços. Em textos e em imagens. Há algo em comum entre elas.

Vamos ver e ouvir jovens viverem e contarem suas histórias de amor, violência, descobertas, frustrações, alegrias.

Assim como fazíamos. E fazemos. E continuaremos a fazer.

Mas, e sobretudo, temos um compromisso: se quisermos mudar aquilo que condenamos, precisamos refletir seriamente sobre o que fomos e o que somos, para que possamos propor caminhos seguros.

A literatura e o cinema podem nos ensinar muito.

\footnotetext{
* Fernando Rıos é jornalista, publicitário, cientista social e consultor em Comunicação Organizacional Integrada.

ISA MARIA F. Rosa Guará é pedagoga, psicopedagoga, doutora e mestre em Serviço Social (PUC-SP), consultora de projetos sociais e de educação e coordenadora editorial dos Cadernos CENPEC.
}

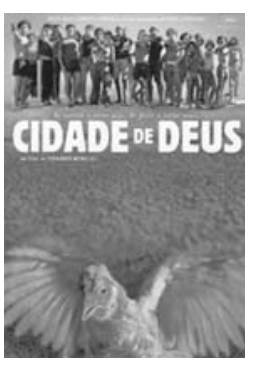

\section{Cidade de Deus}

DIREÇÃO: FERNANDO MEIRELLES

ATORES: Matheus Nachtergale (Sandro Cenoura), Seu Jorge (Mané Galinha), Alexandre Rodrigues (Buscapé), Leandro Firmino da Hora (Zé Pequeno), Roberta Rodrigues (Berenice), Phellipe Haagensen (Bené), Jonathan Haagensen (Cabeleira), Douglas Silva (Dadinho), Jefechander Suplino (Alicate), Alice Braga (Angélica), Emerson Gomes (Barbantinho), Édson Oliveira (Barbantinho - adulto), Luis Otávio (Buscapé - criança), Maurício Marques (Cabeção), Gero Camilo (Paraíba), Graziella Moretto (Jornalista).

BRASIL, DRAMA, 2002, 135 MINUTOS, CORES.

Baseado no livro homônimo de Paulo Lins; Companhia das Letras, São Paulo, SP.

Em um dos locais mais violentos do Rio de Janeiro, um jovem pobre e negro consegue escapar do mundo do crime tornando-se fotógrafo profissional. Buscapé (Alexandre Rodrigues) é um jovem pobre, negro e muito sensível, que cresce em um universo de muita violência. Buscapé vive na Cidade de Deus, favela carioca conhecida por ser um dos locais mais violentos da cidade. Amedrontado com a possibilidade de se tornar um bandido, Buscapé acaba sendo salvo de seu destino por causa de seu talento como fotógrafo, o qual permite que siga a carreira. É através de seu olhar atrás da câmera que Buscapé analisa o dia-a-dia da favela onde vive, em que a violência aparenta ser infinita.

Indicado a quatro Oscar em 2004: Roteiro Adaptado, Fotografia, Montagem e Diretor; ao Globo de Ouro de melhor filme estrangeiro 2003; Prêmio de Melhor Edição no BAFTA, o "Oscar britânico", em 2003; Ganhou nove prêmios no Festival de Havana, nas seguintes categorias: Melhor Filme, Melhor Ator (dividido entre Matheus Nachtergale, Seu Jorge, Alexandre Rodrigues, Leandro Firmino da Hora, Philippe Haagensen, Johnathan Haagensen e Douglas Silva), Prêmio da Universidade de Havana, Melhor Fotografia, Melhor Edição, Prêmio FIPRESCI, Prêmio OCIC, Prêmio da Associação de Imprensa Cubana e Prêmio Grand Coral; ganhou uma menção especial no Festival Internacional de Toronto. 




\section{Billy Elliot}

\section{DIREÇÃO: STEPHEN DALDRY}

ATORES: Julie Walters (Mrs. Wilkinson), Jamie Bell (Billy Elliot), Jamie Draven (Tony), Gary Lewis (Pai), Jean Heywood (Avó), Stuart Wells (Michael), Nicola Blackwell (Debbie).

DRAMA, INGLATERRA, 2000, 111 MINUTOS, CORES.

Billy Elliot é a história de Jamie Bell, de 11 anos, que vive numa pequena cidade inglesa, onde o principal meio de sustento são as minas da cidade. É obrigado a treinar boxe por imposição do pai; mas sua grande paixão é o balé, que passa a dançar escondido de sua família, mantendo sempre o sonho de se tornar um grande bailarino. Recebeu três indicações ao Oscar.

Ambientado nos anos em que Margaret Thatcher esteve no poder, o filme tem como pano de fundo as lutas grevistas dos mineiros.

O filme aborda o preconceito em relação aos homens que se tornam dançarinos e toca na questão da homossexualidade, já que o melhor amigo de Billy é gay, enquanto ele, que adorava a dança não tinha a mesma orientação sexual. Incentivado pela professora de balé, ele resolve abandonar o boxe e se dedicar à dança, mesmo tendo que enfrentar a contrariedade de seu irmão e seu pai à sua nova atividade.

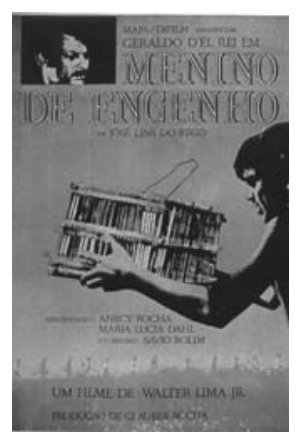

\section{Menino de Engenho}

DIREÇÃO: WALTER LIMA JR.

ATORES: Geraldo Del Rey (Juca), Sávio Rolim (Carlinhos), Rodolfo Arena (José Paulino), Anecy Rocha (Tia Maria), Margarida Cardoso (Sinhazinha), Maria Lúcia Dahl (Maria Lúcia), Antônio Pitanga (Zé Guedes), Maria de Fátima (Clara). DRAMA, BRASIL, 1965, 110 MINUTOS, BRANCO E PRETO.

Baseado no livro homônimo de José Lins do Rego; Editora Jose Olympio, Rio de Janeiro, RJ.

Em 1920, na Paraíba, após a morte da mãe, o menino Carlinhos (Sávio Rolim) é enviado para o engenho Santa Rosa para ser criado pelo avô e pelos tios. Lá ele testemunha a chegada de um novo tempo, com o advento das modernas usinas de açúcar e as transformações econômicas e sociais pelas quais passa a produção canavieira, mudanças que irão afetar a vida de todos. Aos 15 anos, é enviado para o colégio.

Ganhou uma Menção Especial, no Festival de Brasília, o prêmio de Melhor Filme no Festival de Santarém (Portugal); o Prêmio IV Centenário do Rio de Janeiro de Melhor Filme.



\section{0 garoto (The kid)}

DIREÇÃO: CHARLES CHAPLIN

ATORES: Charles Chaplin (Vagabundo), Edna Purviance (Mãe), Jackie Coogan (Garoto), Baby Hathaway (Garoto - bebê), Carl Miller (Artista), Granville Redmond (Amigo), Tom Wilson (Policial), May White (Esposa do policial). COMÉDIA, EUA, 1921, 68 MINUTOS, BRANCO E PRETO.

Sem condições de criar seu filho, uma mãe solteira deixa o bebê no banco traseiro de um carro de luxo. Porém, ele é roubado e a criança acaba sob a guarda de um vagabundo, Carlitos, que faz o papel de um vidraceiro ambulante. Uma tragicomédia que nos remete ao o início do século passado, nos Estados Unidos, para a questão de crianças abandonadas e dos sem-teto. 




\section{Os esquecidos (Los Olvidados)}

\section{DIREÇÃO: LUIS BUÑUEL}

ATORES: Alfonso Mejía (Pedro), Estela Inda (Mãe de Pedro), Miguel Inclán (Don Carmelo), Javier Amézcua (Julian), Mário Ramirez (Ojitos), Francisco Jambrina (Diretor), Jesús Navarro (Pai de Julian), Efraín Arauz (Cacarizo), Jorge Pérez (Pelon), Alma Delia Fuentes (Meche), Roberto Cobo (Jaibo).

DRAMA, MÉXICO, 1950, 85 MINUTOS, BRANCO E PRETO.

Cidade do México, anos 50. o adolescente El Jaibo foge do reformatório e volta para uma vida marcada pela miséria e falta de perspectivas. Ao lado de outros garotos, vive de pequenos assaltos. O líder deles espanca um rapaz até a morte. Considerando-se culpado por ser cúmplice do assassinato, um dos delinqüentes entra em confronto com ele.

Há uma cena memorável em que o menino Pedro mistura a culpa pelo assassinato e por seus sentimentos dúbios pela mãe num mesmo sonho.

Os esquecidos é uma impressionante obra-prima do mestre espanhol Luis Buñuel (1900-1983), diretor dos indesquecíveis: A Bela da Tarde, O Discreto Charme da Burguesia, O Anjo Exterminador, entre tantos outros.

0 retrato realista do cotidiano dos menores abandonados serviu de inspiração para Hector Babenco realizar Pixote, a Lei do Mais Fraco.

Filho de latifundiários e educado por jesuítas, o espanhol Luis Buñuel (1900-1983) fez, do ataque à religião, ao sistema e à moral burguesa, sua missão na vida.

Paulo Ricardo de Almeida traça um perturbador retrato do filme:

Pedro, El Jaibo, Ojitos, Metche e as demais crianças e adolescentes que vagam pelos subúrbios miseráveis da Cidade do México representam os esquecidos e os abandonados pelo mundo dos adultos que, preocupados em impor a lei e a disciplina, negam-lhes amor, carinho, afeto e compaixão (o assustador discurso de Dom Carmelo, que prefere tratá-los como simples criminosos ou como meros animais). Em Os Esquecidos, todos os adultos são personagens ausentes, frios ou abjetos [...] Para Buñuel, a sociedade em que seus jovens personagens estão imersos se encontra tão viciada e tão corrupta que até a inocência infantil já se perdeu por completo.

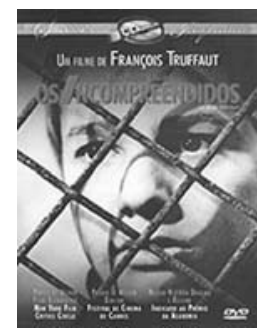

\section{Os incompreendidos (Les 400 coups)}

DIREÇÃO: FRANÇOIS TRUFAUT

ATORES: Jean-Pierre Léaud (Antoine Doinel), Claire Maurier (Gilberte Doinel), Albert Rémy (Julien Doinel), Guy Decomble (Petite Feuille), Georges Flamant (Sr. Bigey), Patrick Auffay (Rene), Richard Kanayan (Abbou), Yvonne Claudie (Madame Bigey), Robert Beauvais (Diretor da escola), Jacques Monod (Comissário), Pierre Repp (Professor de inglês), Henri Virlojeux (Vigilante noturno).

DRAMA, FRANÇA, 1959, 100 MINUTOS, PRETO E BRANCO.

Uma obra-prima. Talvez, a melhor de Trufaut e uma das melhores da história do cinema. Uma história simples - um garoto que não recebe atenção de sua mãe enfrenta problemas com a escola -, maravilhosamente bem contada. O filme constitui-se num dos mais importantes títulos da nouvelle vague francesa e uma das melhores produções do cinema francês de todos os tempos.

Eduardo Veras resume e comenta:

Fotografado em preto-e-branco, Os Incompreendidos acompanha o percurso de um garoto de 12 ou 13 anos pela Paris do final dos anos 50. [...] A criança está sempre se metendo em encrencas, e vem daí o título original, Les 400 Coups - uma expressão idiomática francesa que pode ser traduzida por "pintar o sete". [...] Antoine Doinel mata aula e mente que a mãe morreu, ergue um altar em honra de Honoré de Balzac e quase mete fogo na casa, rouba e se arrepende, é preso e foge. [...] Passados quase 40 anos, o final deve se manter surpreendente. É um dos filmes mais simples e mais belos em cento e poucos anos de cinema. [...] François Truffaut (1932-1984) não gostava de admitir, mas teve uma infância bem parecida com a do protagonista de Os Incompreendidos. Amargou problemas com os pais, aplicou pequenos golpes e acabou confinado num reformatório juvenil.

Truffaut também nos deixou excelentes trabalhos, como: Jules e Jim - Uma Mulher para Dois (Jules et Jim), de 1962; Fahrenheit 451 (Fahrenheit 451), de 1966; A História de Adèle H. (L'histoire d’Adèle H.), de 1975; e A Mulher do Lado (Le femme d'a coté), de 1981. 


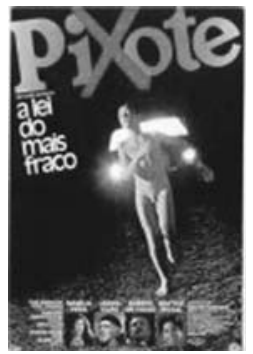

Pixote - A lei do mais fraco

DIREÇÃO: HECTOR BABENCO

ATORES: Fernando Ramos da Silva (Pixote), Marília Pera (Sueli), Jorge Julião (Lilica), Gilberto Moura (Dito), Edílson Lino (Fumaça), Zenildo Oliveira Santos (Chico), Cláudio Bernardo (Garatão), Israel Feres David (Roberto Pie de Plata), José Nílson Martins dos Santos (Diego), Jardel Filho (Sapatos Brancos), Rubens de Falco (Juiz), Elke Maravilha (Débora), Tony Tornado (Cristal), Beatriz Segall (Viúva), Ariclê Perez (Professora).

DRAMA, BRASIL, 127 MINUTOS, CORES.

Pixote foi abandonado por seus pais e rouba para viver nas ruas. Após ser recolhido a um reformatório em São Paulo - que só ajudou na sua “educação”, pois ali ele conviveu com todo tipo de criminoso e jovens delinqüentes - foge em meio a uma rebelião. Sobrevive se tornando um pequeno traficante de drogas, cafetão e assassino, mesmo tendo apenas 11 anos. Nas ruas, na luta pela sobrevivência, Pixote, Dito, Lilica e Chico formam uma espécie de família, mantendo-se de pequenos assaltos. São quase irmãos, sob a liderança de Dito e Lilica, os mais velhos. Numa de suas incursões pelo crime, vão ao Rio de Janeiro levar uma partida de cocaína. Daí para frente, a situação se complica.

Baseado em livro de José Louzeiro.



\section{Quem matou Pixote?}

\section{DIREÇÃO: JOSÉ SOFFILY}

ATORES: Cassiano Carneiro (Fernando); Luciana Rigueira (Cida), Joana Fomm (Iracema), Tuca Andrada (Cafu), Roberto Bomtempo (Lobato), Carol Machado (Ana Lúcia), Maria Luísa Mendonça (Malu), Antônio Abujamra (Advogado), Paulo Betti (Diretor de TV), Maria Lúcia Dahl (Atriz de TV), Antônio Petrin (Comissário), Anselmo Vasconcelos (Diretor de cinema), Thiago Vidal (Fernando - jovem), Orlando Vieira (Louzeiro). DRAMA, BRASIL, 1996, 116 MINUTOS, CORES.

Em 25 de agosto de 1987, Fernando Ramos da Silva, 19 anos, o garoto pobre que ganhou fama ao estrelar o filme Pixote - a Lei do Mais Fraco, foi morto a tiros por PMs em uma favela da cidade de Diadema, em São Paulo.

Já tinha sido preso após um assalto. Depois de solto, voltou à periferia, onde chegou a se casar e teve uma filha. Este filme conta sua história, depois do filme de Hector Babenco. Com o sucesso do filme, ele sai da periferia e tenta continuar na carreira artística, mas as coisas dão errado e ele volta à deliqüência, não escapando de um destino trágico. Vencedor de seis Kikitos no festival de Gramado, inclusive o de melhor filme.



\section{Ser e ter (Être et avoir)}

DIREÇÃO: NICOLAS PHILIBERT

ATORES: Georges Lopez (professor), Alizé (estudante), Axel (estudante), Guillaume (estudante), Jessie (Própria), Johan (estudante), Johann (estudante), Julien (estudante), Laura (Própria), Létitia (Própria), Nathalie (Própria), Marie-Elizabeth (Própria), Olivier (estudante), Franck (Próprio), Kevin (Próprio).

DOCUMENTÁRIO, FRANÇA, 2002, 104 MINUTOS, CORES.

Auvergne, França. Inverno, primavera, verão, quando termina o ano escolar de 2001, em junho. Ali, vamos conviver com o professor Georges Lopez, 55 anos e 30 de ensino, e seus alunos, um grupo de jovens entre quatro e 12 anos.

Este poético documentário retrata a relação entre professor e alunos, a sua tentativa de chegar até eles, muitas vezes impenetráveis na sua timidez, na sua desconcentração. Com a sua ilimitada paciência, Lopez responde às perguntas dos alunos com outras questões, conduzindo-os às respostas através do caminho da compreensão. Ele é amigo, família, educador, mentor.

Apesar de ser evidente a distância que mantém dos seus alunos, a relação que observamos é de amor, de compromisso. Lopez lida com as várias vertentes dos seus alunos com extrema sensibilidade e atenção. Respeitando a sua inocência e ingenuidade, mas thes abrindo as portas de um mundo complexo.

Neste premiado documentário, um professor mostra como é possível levar o mundo para dentro de uma pequena sala de aula multisseriada, no interior da França. Não apenas o mundo do conhecimento puro e frio, mas aquele em que as relações interpessoais estão acima de tudo: amizade, justiça, lealdade, companheirismo e honestidade permeiam as lições, as conversas entre os colegas de classe e o marcante relacionamento deles com o mestre. Fazendo do respeito e da igualdade a chave da comunicação entre crianças de diferentes idades, o professor mostra a elas que, mais importante do que ter, é ser. 


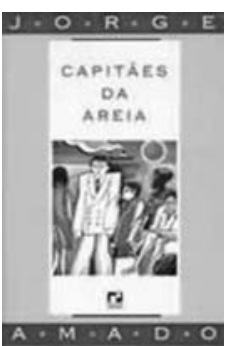

\section{Capitães da Areia / Jorge Amado}

EDITORA RECORD, RIO DE JANEIRO, RJ, 256 PÁGINAS, 2002.

A história dos meninos de rua que povoam e dominam a capital da Bahia inspirou Jorge Amado no seu sexto romance. Publicado em 1937, pouco depois de implantado o Estado Novo, este livro teve a primeira edição apreendida e exemplares queimados em praça pública de Salvador por autoridades da ditadura. Em 1940, marcou época na vida literária brasileira, com nova edição e, a partir daí, sucederam-se as edições nacionais e estrangeiras. A obra teve adaptações para o rádio, teatro e cinema.

Em Capitães da Areia a "cidade alta" de Salvador, na Bahia, serve de cenário. Pedro Bala é o chefe de um grupo de jovens arruaceiros que rouba para sobreviver. Nunca ninguém havia mencionado em literatura este bando de jovens que engenhosamente desafia as autoridades, roubando a classe privilegiada e dividindo o produto do roubo entre os seus camaradas subnutridos.

O romance narra a vida de menores, nas ruas de Salvador, que vivem num barraco abandonado: o líder é Pedro Bala, bom e corajoso; João Grande, o negro bondoso e forte; o Professor, "artista”; Pirulito, místico e introvertido; Dora, amante de Pedro Bala; Gato, elegante e conquistador; Sem-Pernas, revoltado por não ter um "lar”; Volta Seca, afilhado de Lampião.

A narrativa busca ser fiel à realidade, ao abordar o cotidiano destes jovens que tentam driblar seu destino miserável, sua angústia por não haver quem os proteja, falta de comida, de dinheiro, de amor, numa sociedade extremamente injusta que os persegue e quer matá-los.

Jorge Amado nasceu em Itabuna, em 10 de agosto de 1912 e morreu em agosto de 2001. Dentre os seus livros, estão: Os Subterrâneos da Liberdade; Gabriela Cravo e Canela; Dona Flor e seus Dois Maridos; Tenda dos Milagres; Teresa Batista Cansada de Guerra e Tieta do Agreste.

Capitães da Areia faz parte do conjunto de obras líricas, junto com Jubiabá e Mar Morto.

Em 1989, Walter Lima Júnior dirigiu uma série de dez episódios para a TV Bandeirantes baseada neste livro, com Geraldo D’El Rey, Tamara Taxman e atores infantis escolhidos entre menores de rua.



\section{Casa 12 / Letícia Constant}

COMPANHIA DAS LETRAS, SÃO PAULO, SP, 112 PÁGINAS, 2007.

"Eu levei muitos anos fazendo experiências com o texto, até chegar a um momento harmônico em que tirei quase todos os artigos, escrevi algumas frases em língua estrangeira como se fala. Mas sempre quis deixar alguma leveza. Fiz várias experiências, foram muitos anos de escrita". Assim Letícia Constant, jornalista da redação brasileira da Radio França Internacional, refere-se ao seu livro de estréia, Casa 12, lançado pela editora Companhia das Letras.

Em Casa 12, a autora relata as lembranças de sua infância do ponto de vista da menina que ela era na São Paulo do final dos anos 1950. Numa vila na rua Pamplona, próxima da Avenida Paulista, apresenta a casa, centro do seu mundo: a família, galeria de amigos, brincadeiras, vizinhos, momentos difíceis, dias muito, muito felizes, férias na praia, choro no telhado. Ao lado da autora-menina, acompanhamos os primeiros contatos com a perda e a morte.

A jornalista Adriana Brandão resume:

Casa 12 é um livro de memórias, contado com palavras de uma menina de dez anos. Leticia lembra fatos marcantes de sua infância. [...] Misturado com lembranças familiares e pessoais da época, como o som dos bondes ou as divertidas propagandas 
de remédios em forma de poesia, Leticia Constant escreve também sobre o mundo dos adultos, que ela observa e interpreta com um olhar bem pessoal.

0 texto é leve, divertido, solto, sem artigos, marcado pela oralidade da menina.

Com uma concepção gráfica que acolhe primorosamente o universo da narrativa, Casa 12 encanta os leitores de todas as idades com seu despojamento e espontaneidade.



\section{Clarissa / Érico Veríssimo}

EDIÇÃO DE BOLSO, COMPANHIA DAS LETRAS, SÃO PAULO, SP, 216 PÁGINAS, 2005.

Através do olhar de uma adolescente alegre e otimista, Érico Verissimo revela não só a realidade de uma pensão pequeno-burguesa, como também a situação do Brasil e do mundo na década de 1930.

Pertencente à temática urbana da obra de Verissimo, o romance Clarissa é a história de uma jovem de 13 anos que vem de uma cidadezinha do interior do Rio Grande do Sul e mora na pensão da tia Eufrasina, enquanto estuda em Porto Alegre. Sua rotina não é muito diferente da rotina das meninas da sua idade: aborrece-se com algumas matérias da escola, sente saudade da fazenda em sua cidade natal, Jacarecanga, e observa as pessoas que moram na pensão da tia e na vizinhança. É dessa observação que nasce o rico valor psicológico da obra, já que é a partir dela que Érico Verissimo compõe seu personagem central.

Clarissa é o contraponto de Amaro, outro morador da pensão, músico mal-sucedido preso a sonhos passados que o presente recusa-se a concretizar.

Uma das personagens mais conhecidas de Érico Veríssimo, Clarissa percorre sua trajetória com inocência, timidez e cheia de descobertas em três livros do autor - Clarissa, Música ao Longe e Saga. Tendo, como cenário histórico, a década de 30, uma época de transição, na qual uma guerra mundial tinha terminado e outra estava começando a se configurar.



\section{Contos da Infância e da Adolescencia / Luiz Vilela}

COLEÇÃO BOA PROSA, EDITORA ÁTICA, SÃO PAULO, SP, 3ª ED., 80 PÁGINAS, 2006.

Luiz Vilela é um mestre nos contos curtos, nos diálogos precisos. Por meio de sua técnica, a cada dia mais aperfeiçoada, ele nos apresenta personagens que fazem travessuras, brigam e namoram; delicia-nos com sonhos de crianças e os desejos de juventude, um universo feito de sonhos e encantos, decepções e magia.

Mineiro de Ituiutaba, Minas Gerais, Luiz Vilela nasceu em 1942 e lançou, aos 24 anos, seu primeiro livro, Tremor de Terra, com o qual ganhou o Prêmio Nacional de Fiç̧ão e o reconhecimento como exímio contista. Ganhou um Prêmio Jabuti em 1974 pelo livro de contos O Fim de Tudo. Com livros traduzidos nos Estados Unidos, Alemanha, França, Inglaterra e Itália, Vilela vive hoje na sua cidade natal.

A professora Celia Mitie Tamura resume o pensamento de importantes críticos brasileiros sobre ele:

Luiz Vilela [...] é considerado um dos mais importantes contistas brasileiros da atualidade, figurando nas principais antologias, entre as quais, O Conto Brasileiro Contemporâneo, organizado por Alfredo Bosi, e Os Cem Melhores Contos Brasileiros do Século, sob organização de Ítalo Moriconi. Possui seis livros de contos, quatro romances e duas novelas. Seus contos, que representam o melhor de sua obra, são retratos poéticos do cotidiano urbano, classificando-se em contos quase-crônicas, conforme a denominação de Alfredo Bosi para um dos diversos tipos de contos praticados atualmente no Brasil.

Na opinião de Antonio Candido, Vilela segue uma linha de escrita mais tradicional, mesmo sem ser convencional, se comparado aos escritores surgidos a partir da década de 1970, que buscam a inovação a todo custo, pecando pelo excesso de experimentalismo. Vilela, ao contrário, mantém uma prosa discreta, tendo no diálogo o seu ponto de maior destaque. 




\section{Minha Vida de Menina / Helena Morley}

COMPANHIA DAS LETRAS, SÃO PAULO, SP, 336 PÁGINAS, 2007.

Em pequena meu pai me fez tomar o hábito de escrever o que sucedia comigo. Na Escola Normal o Professor de Português exigia das alunas uma composição quase diária [...] Eu achava mais fácil escrever o que se passava em torno de mim e entre a nossa família, muito numerosa. [...]

Não sei se poderá interessar ao leitor de hoje a vida corrente de uma cidade do interior, no fim do século passado através das impressões de uma menina, de uma cidade sem luz elétrica, água canalizada, telefone, nem mesmo padaria, quando se vivia contente com pouco, sem as preocupações de hoje. E como a vida era boa naquele tempo.

Em 1942, aos 62 anos, Helena Morley, pseudônimo de Alice Dayrell Caldeira Brant, revê suas anotações de juventude e resolve publicá-las. Elas contam o pensamento e a visão de uma jovem, dos 13 aos 15 anos, que viveu na cidade de Diamantina, nas Minas Gerais do final do século XIX, quando já não havia diamantes nem riqueza. A dúvida de Helena Morley foi desfeita. Aclamada por Carlos Drummond de Andrade, João Guimarães Rosa e Gilberto Freyre, esta obra, cujas notas vão de uma quinta-feira, 5 de janeiro de 1893, à terça-feira, 31 de dezembro de 1895, tem um lugar especial na literatura brasileira e na história de nossa juventude.

\section{Sites e Portais}

\section{Revista Veja / Jovens}

http://veja.abril.com.br/idade/exclusivo/jovens/

Uma edição especial da revista Veja na Internet, de setembro de 2001.

Edição Especial Veja Jovens. Um retrato da geração mais bem informada de todos os tempos.

\section{Observatório da Infância}

http://www.observatoriodainfancia.com.br/

A história do Observatório da Infância se confunde, entrelaça-se e se relaciona intimamente com a história da Associação Brasileira Multiprofissional de Proteção à Infância e à Adolescência - ABRAPIA, organização não-governamental, idealizada pelo pediatra Lauro Monteiro e fundada no Rio de Janeiro em 1988.

http://www.observatoriodainfancia.com.br/article.php3?id_article $=227$

Endereços das Promotorias da Infância e Juventude nas capitais brasileiras.

\section{Educação Pública}

http://www.educacaopublica.rj.gov.br/

O Portal da Educação Pública é um espaço virtual que oferece atividades de extensão para educadores. Por extensão, entenda-se minicursos e oficinas a distância, cursos semipresenciais, fóruns de discussão, divulgação e produção de textos educativos, científicos ou literários, biblioteca e pesquisa, entre várias outras possibilidades que queremos criar para produzir e intercambiar conhecimentos com educadores. O Portal é fruto do consórcio Centro de Educação Superior a Distância do Estado do Rio de Janeiro - Cederj, que reúne as universidades públicas sediadas no estado do Rio.

http://www.escrevendoofuturo.org.br/

Site do Prêmio Escrevendo o Futuro, da Fundação Itaú Social, coordenado pelo CENPEC traz notícias do Prêmio, textos finalistas, artigos sobre leitura e escrita e depoimentos dos participantes. 


\section{Textos na Internet}

\section{Por uma nova escola}

http://www.desafios.org.br/Edicoes/14/artig012975-3.asp

"Por uma nova escola" é um artigo de Eliana Simonneti para a revista Desafios do Desenvolvimento, uma publicação do Instituto de Pesquisa Econômica Aplicada - IPEA e do Programa das Nações Unidas para o Desenvolvimento PNUD; edição 14, 1 de setembro de 2005.

Aborda uma questão que deveria estar atraindo a atenção de todos, pois diz respeito principalmente às crianças, aos jovens e ao futuro do país: o atendimento mais abrangente e de melhor qualidade na rede pública de ensino.

\section{Disciplina/Indisciplina}

http://www.planetaeducacao.com.br/novo/artigo.asp?artigo=733

A indisciplina na sala de aula, artigo de Sheila Cristina de Almeida e Silva Machado.

http://www.dominiopublico.gov.br/download/texto/ueoooo11.pdf

Educação e conhecimento: a experiência dos que avançaram. Relatório de dois seminários organizados pela Organização das Nações Unidas para a Educação, a Ciência e a Cultura- UNESCO, em setembro de 2003, Brasília. Apresenta experiências de sucesso da Coréia do Sul, Malásia, Espanha, Finlândia, Reino Unido e Irlanda.

\section{François Dubet}

http://www.scielo.br/scielo.php?script=sci_arttext\&pid=S1517-45222003000100007

Artigo de Anne Marie Wautier, professora na UNIJUÍ (RS), doutoranda em Sociologia na UFRGS: Para uma sociologia da experiência. Uma leitura contemporânea: François Dubet.

http://www.anped.org.br/rbe/rbedigital/RBDE17/RBDE17_03_FRANCOIS_DUBET.pdf

As desigualdades multiplicadas, artigo do sociólogo francês François Dubet.

http://www.anped.org.br/rbe/rbedigital/RBDE05_6/RBDE05_6_19_ANGELINA_E_MARILIA.pdf

Quando o sociólogo quer saber o que é ser professor, entrevista com François Dubet.

\section{Julio Groppa Aquino}

http://www.crmariocovas.sp.gov.br/ent_a.php?t=001

Neste endereço, podem ser acessados uma entrevista e dois artigos do professor Julio Groppa Aquino: $A$ violência escolar e a crise da autoridade docente e $A$ indisciplina e a escola atual.

http://www.proceedings.scielo.br/scielo.php?pid=MSC0000000082005000100002\&script=sci_arttext Jovens “indisciplinados" na escola: quem são? Como agem? Artigo do professor Julio Groppa Aquino para o Simpósio Internacional do Adolescente, de 2005, em São Paulo. 


\section{Cadernos Cenpec}

ANO 2

NÚMERO 4

SEgundo SEMESTRE DE 2007

Cadernos Cenpec é uma publicação do

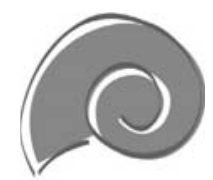

\section{CENPEC}

Cenpec - Centro de Estudos e Pesquisas em Educação, Cultura e Ação Comunitária

Rua Dante Carraro, 68

05422-060 - São Paulo - SP

Brasil

Telefax: (55) (11) 21329000

cenpec@cenpec.org.br

www.cenpec.org.br

Os artigos assinados não representam necessariamente os pontos de vista do CENPEC. As opiniões e idéias expressas neles são de responsabilidade exclusiva de seus autores.
Cenpec

Centro de Estudos e Pesquisas em Educação, Cultura e Ação Comunitária

\section{PRESIDÊNCIA}

Maria Alice Setubal Diretora Presidente

Ricardo Campus CaIUby Ariani Diretor Vice-Presidente

Diretores Administrativos

LYDIA MARIA QUEIROZ FERREIRA DE MAGALHÃES

TEREZA MARIA MACEDO SOARES DE ARAÚJO

Conselho de Administração

Antonio Carlos Caruso Ronca

Bernadete Angelina GatTI

HÉLIO MATTAR

Maria Alice Setubal

Michel Paul ZeItLin

RicARdo CAMpos CAIUBy ARIANI

Conselho Fiscal

Reginaldo José CAMILO

Rebecca de Castro Filgueiras Raposo

Coordenação

Coordenadora Geral

Maria do Carmo Brant de Carvalho

Assessoria da Coordenação

MARIA ÂNgela LeAL Rudge

MARIA CRISTINA S. ZELMANOVITS

MARIA AMABILE MANSUTTI

Coordenadora Administrativo-Financeira

MARIA Aparecida Acunzo Forli 


\section{Créditos desta edição}

Organização e Coordenação

ISA MARIA F. ROSA GUARÁ

Comitê Editorial

Ana Regina Carrara

ELOÍSA DE BLASIS

FERNANDO RIOS

ISA MARIA F. ROSA GUARÁ

Maria do Carmo Brant de Carvalho

Conselho Editorial

ÂMBAR DE BARROS

Antonio Jacinto Mathias

Bernadete GatTI

Fernando Almeida

FERNANDO ROSSETTI

Gilda Portugal Gouveia

ISA MARIA F. ROSA GUARÁ

Marco Aurélio Nogueira

Maria Alice Setubal

Maria do Carmo Brant de Carvalho

VERA MASAgÃo

Tiragem

2.000 exemplares

Colaboram nesta edição:

Ana PAula de Oliveira

Cristina Fernandes de Sousa

ElizABete D’ Assunção José

JULIO GROPPA AQUINO

MARIA AMABILE MANSUTTI

Maria Aparecida Perez

MARIA CRISTINA ZELMANOVITS

Maria do Carmo Brant de Carvalho

MARIA ESTELA BERGAMIN

Maria José Reginato Ribeiro

MARIA MALTA CAMPOS

MeYri VenCl ChIEFfI

NORMAN GALL

Sheila Roberti Pereira da Silva

VANDA NOVENTA FONSECA

VERÓNICA GURIDI

YARA SAYÃO

ZORAIDE FAUSTINONE

Cadernos Cenpec / Centro de Estudos e Pesquisas em Educação, Cultura e Ação Comunitária. - N. 4 (2007) -

São Paulo: CENPEC, 2006

ISSN 1808-963002

Semestral

1. Educação 4. CENPEC

CDD 370 


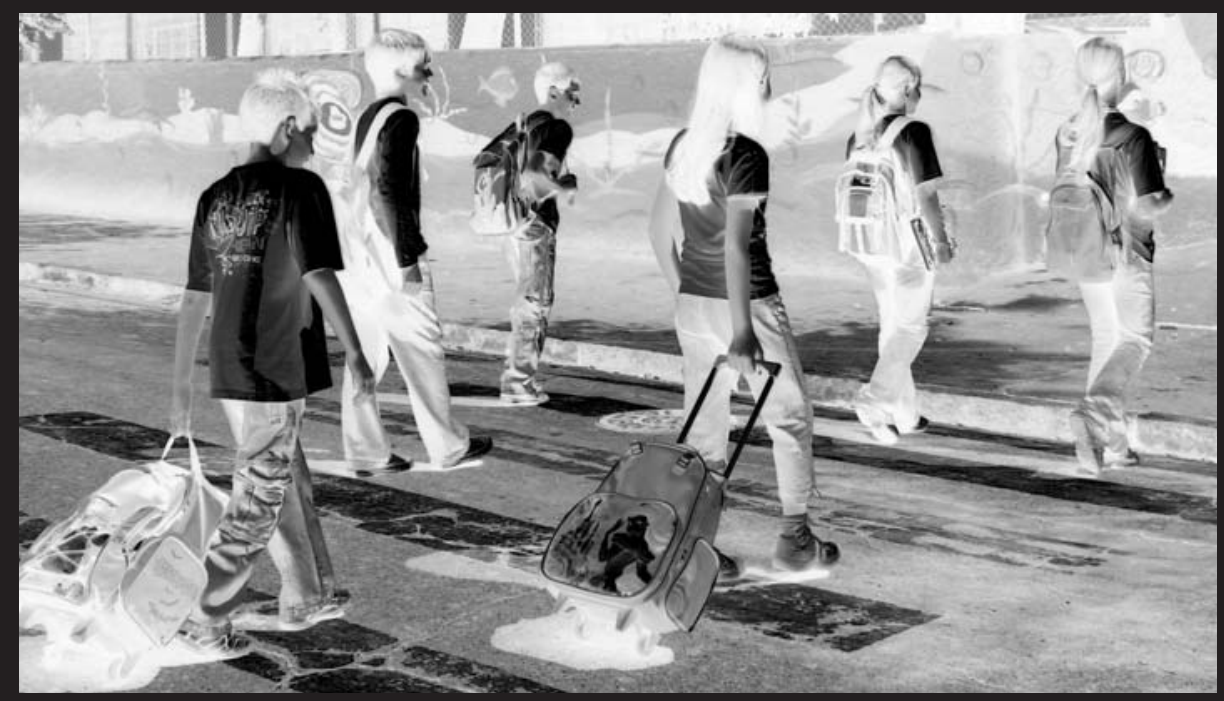

